\title{
Dipirona nas concentrações de $1 \%$ e $10 \%$ não produziu analgesia por via subaracnóide em ratos
}

\author{
CET do Departamento de Anestesiologia da Faculdade de Medicina \\ da Universidade de São Paulo, São Paulo
}

INTRロDUÇÃ̃

O efeito analgésico da dipirona ainda não está claramente elucidado, parecendo concorrer mecanismos periféricos e centrais, encontrando-se evidências de existência de sítio de ação no corno dorsal da medula espinhal, em áreas rostrobulbares mediais e na substância periaquedutal cinzenta.

MÉTロDOS

Após aprovação pela Comissão de Ética, 15 ratos machos, pesando entre 300 e $350 \mathrm{~g}$, foram submetidos ao teste dos filamentos de von Frey na pata direita. Os animais, em seguida, foram anestesiados com halotano e realizou-se a punção lombar. Foram divididos em três grupos que receberam, respectivamente, $0,001 \mathrm{ml}$ de solução fisiológica, $0,001 \mathrm{ml}$ de dipirona $1 \%$ e $0,001 \mathrm{ml}$ de dipirona $10 \%$. A dor era produzida pela incisão cirúrgica, divulsão e sutura na região plantar da pata posterior direita. O teste dos filamentos de von Frey era aplicado às 1o, 2o e $4^{\circ}$ horas após o estímulo doloroso. Os dados foram analisados por medidas repetidas pelos testes de análise de variância e bonferroni.

\section{RESULTADIS}

Em todos os grupos houve redução dos valores ao teste dos filamentos de von Frey quando comparados aos valores anteriores à incisão cirúrgica. Os valores não foram diferentes entre os grupos, nem no mesmo grupo nos momentos
$1 \mathrm{~h}, 2$ h e $4 \mathrm{~h}$. No grupo dipirona, às $4 \mathrm{~h}$, os valores do teste de von Frey foram maiores que os de $1 \mathrm{~h}$. Os valores também não foram diferentes entre os grupos nos momentos $1 \mathrm{~h}, 2 \mathrm{~h}$ e $4 \mathrm{~h}$.

DISCUSSÃロ

Esses resultados sugerem que a dipirona $1 \%$ ou $10 \%$ não promove analgesia que possa ser identificada pelo teste dos filamentos de von Frey nos intervalos de tempo deste estudo.

CロNCLUSÃロ

Os resultados denotam que a dipirona a $1 \%$ ou $10 \%$ não apresenta atividade antinociceptiva nesse modelo de dor, quando administrada por via subaracnóidea.

REFERÊNCIA

Vanegas H, Tortoci V, Eblen-Zajjur A, et al. Microinjeted dipyrone (metamizol) inhibits responses of spinal dor sal horn neurons to natural noxious stimulation in rats. Brain Res. 1997;759:171-4 